\title{
4 Electric vehicles and the future of personal mobility in the United Kingdom
}

\author{
Noam Bergman
}

\section{Introduction}

The future of transport, and specifically, the question of how to achieve sustainable personal mobility, is a much-debated topic, considering environmental issues such as air pollution, inequality of access to mobility and urban traffic congestion. Further, growing concerns over climate change have put pressure on the transport sector to reduce its greenhouse gas emissions. Transport accounts for approximately 25 per cent of the UK's $\mathrm{CO}_{2}$ emissions, nearly two-thirds of which comes from cars and vans (CCC, 2014). There are also major concerns over air pollution and road congestion.

However, changes to the road transport system are considered especially challenging. In the UK, like other countries in the developed world, road-based transport centred on the private car for personal mobility is dominant. Discourses among transport professionals and policymakers portray unrestricted mobility as a right (Doughty and Murray, 2016). A UK government-issued review on low-carbon cars opened with the statement 'Road transport underpins our way of life' (King, 2007, p. 3), and ties road transport with economic growth and technological progress, an approach still evident in the recent Industrial Strategy (HMG, 2017). The UK has a large automotive industry, with a turnover of $£ 77.5$ billion, employing over 800,000 people, including 169,000 in manufacturing (SMMT, 2017), making change politically and economically challenging. Overall, the UK is locked into automobility, where privately owned car use is reinforced by infrastructure, regulations, institutions, vested interests, norms, cultures and practices (Paterson, 2007; Schwanen, 2015; Urry, 2004). A significant shift towards sustainable personal mobility therefore requires systemic change - a sociotechnical transition.

Various technological and cultural innovations exist with the potential to make transport more sustainable, such as low-emission vehicles, integrated transport, and car-sharing clubs. A prominent example is electric vehicles (EVs) - an innovation with technical potential to reduce emissions from road transport, if powered by low-emission electricity. However, consumer uptake has been very slow, and EVs have met resistance from within the traditional automotive industry and ambivalence from policymakers. That might be changing 


\section{Noam Bergman}

with a variety of EVs available on the market in different countries. In the UK, sales have risen steeply in the past few years, with 37,000 new EVs ${ }^{1}$ registered in 2016, and 47,000 in 2017 - nearly 1.9 per cent of total sales (SMMT, 2018). While EVs might leave many aspects of automobility intact, they have the potential to significantly change the transport system through diverse electrified transport not limited to cars, causing tension with existing industry, infrastructure and driving and refuelling norms.

This chapter considers future visions of personal transport, as imagined by influential transport policy and automotive industry actors. It builds on a recent study (Bergman, 2017; Bergman et al., 2017) that looked at visions of the future of UK road transport, by analysing documents including forecasts, pathways and scenarios by diverse transport sector actors in order to explore how current challenges are perceived, what strategies these incumbent (i.e. regime) actors follow, and what role EVs might have. This chapter continues that research with a transitions theory perspective, complemented by concepts from institutional dynamics.

The research found that regime actors' visions reflect regime actor strategies: in most visions there is a similar trajectory of continued automobility, which offers little discontinuity or disruption compared to the present and recent past, but rather favours gradual change with conventional vehicles prominent in the medium term, and radical innovations institutionalised to reduce their threat. This chapter argues that the creation of visions is an act of 'institutional work' by incumbents, aimed at shaping the future to minimise change that could undermine their power.

We next consider useful concepts from transition theory and institutional dynamics, and the role of visions of the future in these, before introducing the challenge of automobility and sustainable transport through these lenses.

\section{Theoretical background}

\section{Transitions}

This chapter considers two aspects of transition theory: First, regime actors and their strategies, and the dynamics of regime-niche interactions, for example, whether niche-regime relationships are competitive or symbiotic; the latter occurs when radical innovations are seen as complementary to the interests of regime actors and they become absorbed in the prevailing sociotechnical system (Geels and Schot, 2007). Bakker (2014) considers when incumbent actors might strategically support an innovation, considering that newly emerging systems might align with their short- or long-term interests, and that individual or collective expectations might guide them to engage with the innovation. Positive collective expectations of an innovation, which might serve an actor's long-term interests, could lead to supporting a transition (and therefore the innovation) through influencing the configuration of the emerging system 'just in case the transition does take place' (Bakker, 2014, p. 65). 
Second, potential future trajectories of the transport system, including personal mobility, could be viewed using the typology of transition pathways (Geels and Schot, 2007) described below. These pathways are archetypal, and a transition could involve elements of different pathways, or begin following one pathway and continue in another. ${ }^{2}$

When there is ongoing moderate landscape pressure on the regime, but niches are not sufficiently developed to pose a threat, regime actors can respond by modifying trajectories and innovation activities, possibly adopting ideas from niche innovations, with cumulative readjustments. The regime changes trajectory, but its basic architecture remains largely unchanged in a transformation pathway. In some instances, the adopted innovations trigger further changes in the architecture of the regime, with ongoing adoption leading to changes to rules, technologies, policy and user practices, all accumulating to a major reconfiguration. Struggles between policy actors and industry are possible in both these pathways (Smink et al., 2015).

If a large, sudden landscape change occurs and incremental change is insufficient, the regime struggles in competition between incumbents and newcomers. If developed niche innovations exist, one innovation can ultimately break through to replace the existing regime, in a (technological) substitution. If, on the other hand, niches are insufficiently developed, regime actors might lose faith leading to collapse, or de-alignment, of the regime. There is a period of competition between co-existing niches, leading to multiple innovation trajectories - but also uncertainty. Eventually, one niche will win out and a new regime will be formed, completing the de-alignment and re-alignment pathway.

In the absence of strong landscape pressure, the regime exhibits dynamic stability in a reproduction pathway. Even in reproduction, regime actors need to act in order to maintain power.

\section{Visions}

It is well established that visions of the future, and the expectations they generate, are central to the process of technological innovation. Visions can motivate engineers and designers to initiate projects (van Lente, 1993), be used to attract financial support for research and innovation (Fujimura, 2003), and raise interest from a wide range of stakeholders, increasing an innovation's legitimacy and uptake (Geels and Verhees, 2011; Schot and Geels, 2008). Studies like Levidow and Papaioannou (2013) suggest the importance of visions for innovation processes in personal transport, considering different innovation pathways for different visions.

Uncertainty plays an important role in sustainability transitions, due to long time horizons and large investments, in which societal change and other (landscape) effects occur in addition to innovation and technological development. This suggests visions could be especially important in the transitions approach (Budde et al., 2012).

Visioning is a deeply political technique. Visions created by regime actors are part of the sociotechnical system's 'culture', and therefore might influence 
expectations and strategies of all actors. Regime actors can use visioning exercises to suit their ends: delay pressures, neutralise some risks and threats (e.g. perceived uncertainties over incumbent technologies ability to adapt) while sensitising audiences to others (e.g. end-users' unfamiliarity with yet-to-beproven technologies), and present the future as a more or less linear extrapolation of the (recent) past. This is one reason why genuinely new or unexpected events or systemic changes are rarely considered in visioning exercises. Meanwhile, niche actors can deploy visions to enhance their legitimacy by building networks and gathering support and resources for their innovations (Schot and Geels, 2008).

\section{Institutional dynamics}

Recent thinking on institutional dynamics (Fuenfschilling and Truffer, 2014; Geels, 2014; Smink et al., 2015) suggests that regime actors must work to uphold incumbent institutions, as these 'do not automatically persist. Instead, they need constant maintenance' (Fuenfschilling and Truffer, 2016, p. 301). Rather than reacting to developments, incumbents seek to proactively shape the institutions through which they interact with other social groups. This institutional work includes lobbying policymakers by incumbent firms and, vice versa, policymakers reaching out to incumbent service or technology providers; communication with the general public via advertising, press conferences and releases, and information/education campaigns; commissioning research and technical reports; the formulation of technical standards; and the shaping of discourse (Geels, 2014; Smink et al., 2015). In Multi-Level Perspective (MLP) terms, the dynamic stability of the regime is maintained by regime (incumbent) actors performing institutional work to maintain power in the present and shape the future to reproduce present power structures.

Pulling these strands together, this chapter suggests that visioning is a powerful and effective strategy of institutional work. First, because the formation of visions draws on the imagined future to justify action in the present (Anderson, 2010; McCormack and Schwanen, 2011). Second, because visioning exercises allow actors to 'craft' development trajectories that suit their agendas. A vision of the future with clear expectations (Geels and Verhees, 2011), framed as technological progress with market potential (Ruef and Markard, 2010) can help an innovation secure legitimacy and get the public onside (Walker et al., 2010).

\section{Automobility}

\section{A powerful regime}

The UK transport system is underpinned by the regime of automobility. This can be described by rules that favour privately owned cars; see car mobility as both a right and a necessity; link (car) mobility to economic development and 
technological progress; and see cars as (capable of) becoming green and clean through technological change (e.g. Schwanen, 2015). There are widely shared expectations of (relative) continuity of the system, and so far, the automobility regime has remained dynamically stable.

Regime actors include the automotive industry and transport bodies, but also many planners, consultants and policymakers because their livelihoods and/or the wider social or political-economic orders of which they are part depend on automobility's endurance (Cohen, 2012; Paterson, 2007; Unruh, 2000). Path dependencies also derive from the lifestyles of numerous households, and the sunk investments in road infrastructure and car manufacturers' production processes (Driscoll, 2014; Penna and Geels, 2015). Increasing returns and adaptive preferences, as well as 'interlinked networks of dependency' to the sociotechnical systems of housing development and fossil fuel extraction further entrench the automobility regime (Driscoll, 2014; Penna and Geels, 2015; Urry, 2004; Wells and Nieuwenhuis, 2012).

\section{Potential for change}

While the automobility regime is powerful and enduring, there are a range of landscape dynamics putting pressure on the regime in recent years, which might have weakened it in the long run, thereby opening a window of opportunity (Budde et al., 2012). Increased concerns over climate change and air pollution have led to tighter regulation and legislation. Private car use and ownership have stabilised and even declined across much of the Global North since around 1990, especially among younger people and in cities - described as peak car (Goodwin and Van Dender, 2013). Cultural change has led to the image of the car shifting from an 'icon of modernity' to a more utilitarian perspective (Cohen, 2012). Finally, there seems to be a reduced commitment of policymakers to automobility (Geels, 2012), e.g. actors at the European Level (EU) level have increasingly challenged the automobility regime over the last 20 years through regulations on $\mathrm{CO}_{2}$ emissions and proposed roadmaps towards sustainable mobility (Weyer et al., 2015). In conjunction with these trends, there is a differentiation of strategy among car manufactures and other incumbents (Budde et al., 2012): different firms might make different choices in terms of investment in $\mathrm{EV}$ s, other technologies, or improved internal combustion engine vehicles (ICEVs).

EVs may benefit from this differentiation as a long-standing innovation that has until now remained a niche. They offer a technological solution, while seemingly minimising behaviour and cultural change, although major infrastructural and industry changes are implied - including a reduction in oil consumption. Until recently, EVs had little involvement from regime actors (van Bree et al., 2010), with sales and performance too low to be considered a serious threat. However, this has changed in recent years. All major car manufacturers now produce EVs, suggesting that the industry has 'picked its winning technology' (Bakker and Farla, 2015). Moreover, recent sales across 
the developed world, while still modest, suggest uptake is accelerating beyond the demonstration phase (Bakker and Farla, 2015; Nykvist and Nilsson, 2015). There is undoubtedly increased hype around EVs, with the Organization of the Petroleum Exporting Countires (OPEC) increasing their 2040 forecast for plug-in EVs by nearly 500 per cent from 2015 to 2016, and the International Energy Agency more than doubling its central forecast for 2030 EV fleet size (BNEF, 2017). However, taking the long-term view of a transition, it is too soon to say if this is another hype cycle that will be followed by disappointment, or the beginning of a transition to electric transport.

\section{What would a transition to EVs look like?}

Looking at potential transitions to EVs in Germany, Augenstein (2015) finds discrepancies between visions of the future based on sustainable electric mobility, and strategies rooted in the current regime; battery EVs as a techno-fix could jeopardise 'deeper' sustainability transitions to lower car dependency. Augenstein concludes that EVs cannot simply replace ICEVs, as they are a radical innovation that does not fit the current mobility regime. Success depends on the emergence of 'new functionalities' (Geels, 2005) that ICEVs can't offer, such as EV-based energy storage, or even EVs as mobile power supply and others we cannot predict. This could imply redefining the role of the car in society, matching the technological substitution pathway.

Van Bree et al. (2010) construct future transport visions using transition pathways. Some of their scenarios envision government measures to reduce emissions as the main driver for change, forcing manufacturers to scale up lowcarbon vehicles experiments. EVs winning out requires entrance of new actors and significant change to rules and practices (e.g. reduced driving range and overnight recharging), suggesting a transition pathway of regime de-alignment and re-alignment. Other scenarios envision consumer preferences and high fuel prices forcing manufacturers to change. EVs win out if fast recharging infrastructure is rolled out, with ongoing systemic changes suggesting regime reconfiguration.

These different perspectives suggest a transition to EVs would cause significant disruption to the automobility regime. It follows that regime actors would attempt to either prevent a transition to electric mobility, or reduce the disruption by performing maintaining institutional work, which can alter technology's design, function, practices and image during its diffusion process (Fuenfschilling and Truffer, 2016). In transition terms, regime actors are expected to work towards a transformation pathway if reproduction is no longer tenable; however, the systemic changes EVs would cause to the entire transport system might make this more of a reconfiguration. Lending a historical perspective, Dijk et al. (2015) suggest that when EVs emerged in European markets in the mid-1990s, the transport regime protected itself by transforming and adapting the potentially disruptive innovations of EVs, by favouring hybrid cars (regime sustaining) over battery-EVs (disruptive). 


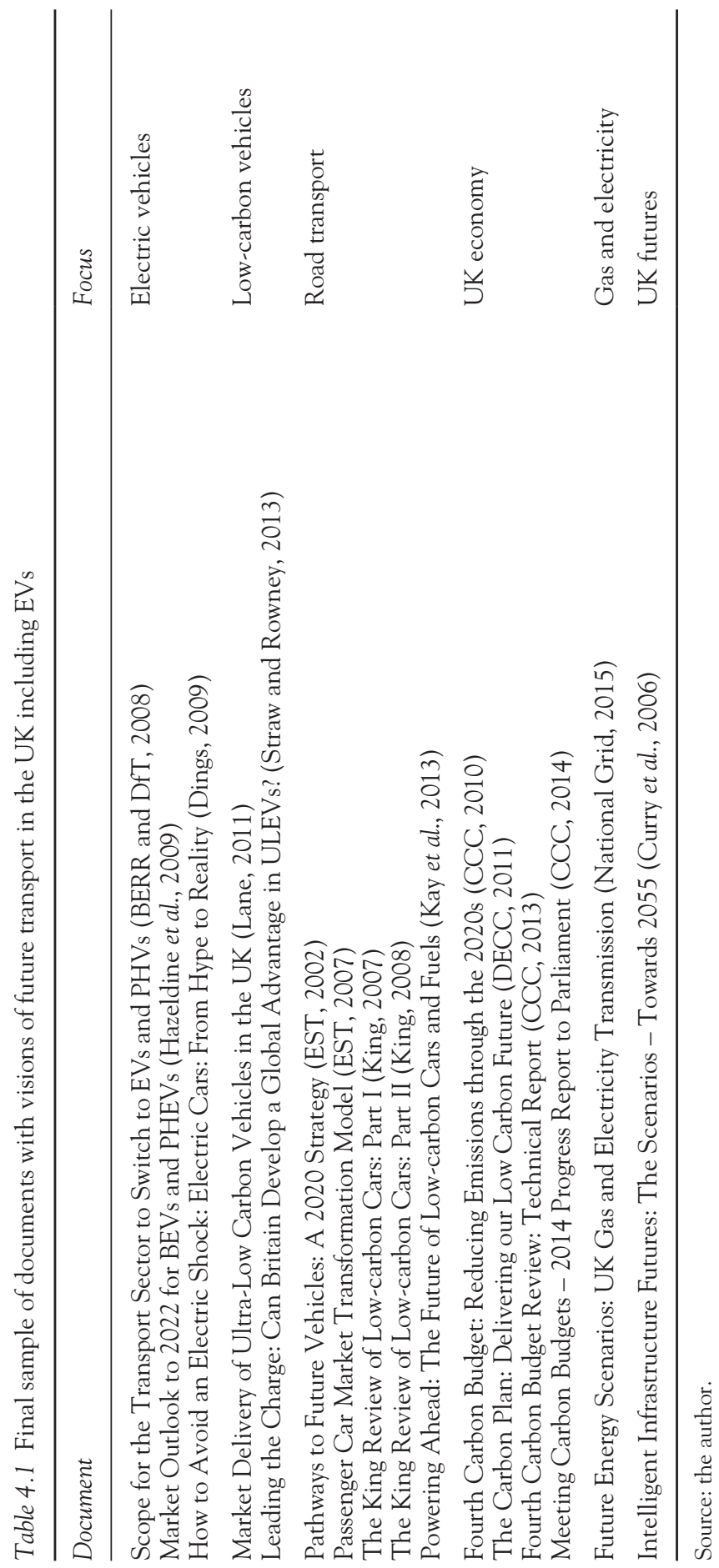


This chapter builds on previous work in considering the connection between visions of the future of personal mobility in the UK as they are constructed and used by incumbent (regime) actors and transition theory, specifically transition pathways and regime-niche interactions.

\section{Methodology}

The main research method was analysis of documents that discuss the UK's transport future. Documents were found through online searches and references in reports and academic papers. These documents were written by, and for, a range of stakeholders in the UK transport sector, including government, industry, consultancies and other bodies. Only documents that explicitly discuss EVs as part of the UK's transport future, and which contain projections about the mid-term future (2020s through 2050s) were selected. Over 30 documents published in 2002-2015 were identified and 16 were selected for in-depth textual analysis, still giving a wide range of perspectives. These are listed in Table 4.1.

The documents were coded through quantitative content analysis. A priori coding included searches for projections of future transport and factors separating different scenarios, such as drivers and barriers for innovation and uptake. Further coding looked for emerging themes and narratives. Some qualitative analysis was also used to understand the tone and context and to infer actors' agendas and strategies. ${ }^{3}$

The documents appear to be dominated by visions from incumbents (regime actors). This might be partly an artefact of the research approach. However, this might also be (partly) a consequence of the deliberate attempts of incumbents to engage in institutional work seeking to absorb EVs into the deep structure that has ensured the survival of automobility since at least the Second World War (cf. Geels, 2011). Moreover, incumbents are more likely to possess the resources and skills to produce the sort of system-level visions that are considered here.

\section{Findings: visions and trajectories}

The analysed documents were produced by a range of actors and are different in style and substance. Some use model forecasts, some review scenarios from other sources, and some use heuristic scenarios or storylines, demonstrating what 'could be' achieved. Nonetheless, there are some clear common themes emerging in the future trajectories, which one might call a 'central vision'. This section explores the central vision, the factors and assumptions underlying it, and highlight trajectories which notably diverge from it. The timeline of the central vision is briefly described in Figure 4.1.

\section{The central vision}

The most striking feature of this near-consensus future is that almost all of the visions analysed are dominated by an assumption of continued automobility. 


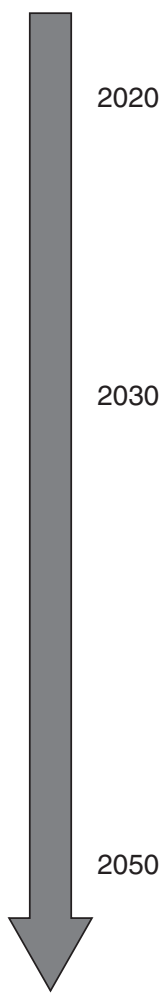

In the years to 2020 , emission reductions could be achieved through efficiency of conventional cars (ICEVs), sometimes 2020 considered 'easy wins' (CCC, 2014; DECC, 2011; EST, 2007; King, 2007). Alternatively, electric vehicles (EVs) and other low-carbon vehicles (LCVs) could reach hundreds of thousands by 2020 .

For 2030 the general picture is of mixed ICEVs and LCVs. Hybrids, plug-in hybrids and EVs, or a mixture of these technologies, are all possible, with fuel cell-powered cars plausible if EVs fail to deliver.

2030 However, uptake rates of LCVs vary significantly, depending on technological development and public attitudes; ICEVs are still a significant part of the stock. While details differ, most trajectories see an upturn in LCV uptake in the 2020s or 2030s.

The pressure of the 2050 target leads a couple of visions to suggest that 100 per cent of new cars need to be battery electric by 2035 (CCC, 2010) or 'near zero tailpipe emissions' for new cars by 2040 (DECC, 2011). Plug-in hybrids and battery EVs can lead to a 90 per cent reduction in emissions, reliant on decarbonisation of the grid (King, 2007; Lane, 2011), although some ICEVs are still expected to be on the road, probably hybrids. Overall, the

2050 suggestion is of almost complete decarbonisation of road transport by 2050 .

Figure 4.1 Timeline of the central vision.

Source: the author.

Even the most recent documents do not take into account the 'peak car' phenomenon, but use long-standing, powerful discourse in which car-based road transport is central to mobility and tied to progress and economic growth. These visions assume that the UK's high travel demand will continue through 2020, 2030 or 2050, and that it will be met mostly through privately owned vehicles.

Many of the forecasts focus on what technology or fuel will power the cars of the future, as opposed to how or how much people will travel, or the broader question of the role the (private) car in the future. The challenge of reducing emissions is therefore seen primarily as a technical question of the distribution of different vehicle types. While the great reduction in emissions is seen as challenging, in almost all detailed scenarios the targets are met.

Another feature of the central vision is the link between automobility and a strong economy. Some documents explicitly link low-carbon vehicles (LCVs) to economic growth, suggesting the UK automotive industry can use its excellence in ICEV production to reach the forefront of LCV production. Further, it 


\section{Noam Bergman}

is suggested that this engineering and manufacturing would deliver jobs and growth. Perhaps the most optimistic vision suggests the transition to LCVs has 'the potential to create jobs, rebalance the British economy towards manufacturing and exports, and promote sustainable economic growth in the UK' (Straw and Rowney, 2013, p. 8).

\section{Factors affecting trajectories}

There are many factors that are seen as affecting EV trajectories, including technology, public acceptance and uptake, policy, and economic factors.

Technological innovation is seen as a necessity for EVs to become mainstream in many visions, and most prominent is the battery - its performance, weight, price and reliability. Battery improvement is seen as essential for market penetration, as EVs have to compete both with ICEVs and with other low-carbon technologies. Battery cost is often portrayed as the most significant and least controllable factor affecting EV market penetration, but battery weight and lifetime, range and recharging times are also considered significant barriers.

While there is a common assumption that technological progress will act as a driver, uncertainty around specific technologies is commonly highlighted. This includes EVs, but also the rate of improvement in ICEVs and the rate of electricity decarbonisation; the collective effect is that the advantage of EVs is positioned as unknown (Dings, 2009; Lane, 2011). The earliest document (EST, 2002) is highly pessimistic about EVs, considering hydrogen more promising. There is more optimism later, suggesting EV rollout depends only on price coming down, although there is also acknowledgement of hype around EVs (e.g. Dings, 2009).

Technical issues and public acceptance issues overlap, for example, nearly every vision suggests that limited vehicle range and high upfront cost are crucial barriers to uptake. Lack of variety of car models and brands is seen as a barrier to uptake, suggesting EVs must mimic ICEVs in performance and choice, and meet expectations of comfort and speed, if they are to be widely purchased (CCC, 2014; EST, 2007; King, 2007). It appears that, with increasing confidence in EV technology over time, there has been a shift towards greater focus on public acceptance and awareness, with EVs' image seen as crucial to success. For example, Lane (2011) suggests manufacturers are rising to the challenge of developing low-carbon cars, leaving demand as the central obstacle.

Many of the documents portray people as fairly homogenous consumers having a passive role in any transition, limited almost exclusively to the choice of vehicle they purchase. Other behaviours, such as modal shift, trip reduction and eco-driving are not linked to EV trajectories; they appear to be seen as too marginal to significantly affect car sales. This is tied to the assumption that technological breakthroughs are needed if EVs are to succeed because of the presumed behavioural inertia and resistance from users, leaving little room for adaptation among consumers. The central vision seeks to replace ICEVs with LCVs with limited behaviour change or other disruption, indirectly delaying 
LCVs until they can easily replace ICEVs. So, despite highlighting the need to create and sustain acceptance demand for $\mathrm{EV}$ s, consumers are not generally perceived as a driving force in the documents, in contrast with some scenarios of van Bree et al. (2010).

The role of government through policy and legislation has been described as 'the single biggest influence on the future of low-carbon cars and fuels' (Kay et al., 2013, p. 123). Various market interventions to support EVs are discussed, including subsidies to reduce upfront price; other incentives for purchase, such as free parking or bus-lane use; investment in technologies through $R \& D$ funding; demonstration and commercialisation programmes, such as procurement of fleet vehicles; and supporting infrastructure.

Visions are also affected by economic forecasts. Most notably, the economic downturn in 2008 led to a drop in car manufacturing volumes, leading Hazeldine et al. (2009) to base their scenarios on severity of recession and speed of recovery, as these could affect development and deployment of EVs. The Committee on Climate Change pushed back its 2010 estimate (CCC, 2010) of EVs reaching cost-effectiveness in the mid-2020s to 2030 in a 2013 estimate (CCC, 2013).

These factors show that the central vision is not inevitable but relies on a variety of assumptions about the future. This makes it all the more important to contrast it with alternative visions, of which there are disappointingly few in these documents.

\section{Specific trajectories of interest}

A few visions have specific trajectories of interest, which challenge some of the assumptions above or stray significantly from the central vision. They both expose (often implicit) assumptions and agendas in the central vision and highlight different responses to the challenges the regime faces.

One vision (Kay et al., 2013) contrasts an 'evolutionary' EV trajectory, which fits the central vision, with a 'revolutionary' trajectory. In the latter, new market entrants revolutionise vehicle design and manufacturing, introducing Information Computer Technology (ICT)-connected cars and compact, lighter (and therefore cheaper) designs suitable for shorter distances, leading to rapid uptake beginning in cities. The description suggests new functionalities, some still unknown, play a part. This is one of the only trajectories across all the analysed documents to suggest disruption, rather than incremental change, leading to greater institutional changes and potentially new norms around travel, a significant deviation from the central vision.

The Foresight work (Curry et al., 2006), based on consultations with stakeholders from business, research and the public sector, is an outlier in its future visions. Its four scenarios are built around the two biggest uncertainties: whether technological progress will indeed deliver a low-carbon transport system, and whether people will accept intelligent infrastructure. Questioning the success of technology, independent from public acceptance, deviates from the consensus 


\section{Noam Bergman}

vision, and allows for futures that depart significantly from the present and recent past. Questioning public acceptance and according a significant, active role to the wider population also contrasts with the central vision, where user practices are principally seen as barriers to EV uptake.

Finally, the National Grid (2015) vision considers electricity use throughout the economy, including future projections of EVs. It differentiates trajectories by level of prosperity and level of 'green ambition'. This is the only document that considers the level of social ambition to decarbonise the economy, as opposed to actions by government, industry or consumers. Only one of their four scenarios, which has an environmentally engaged society and moderate economic growth, achieves the UK's renewable energy and emission reduction targets on time. This is the only document that explicitly constructs scenarios that fail to meet the targets, highlighting presumed success in many others.

\section{Discussion and analysis}

This section considers how the visions reflect actors' strategies, offering an analysis from a transition pathways perspective and an institutional work perspective, noting that some actors might consider LCVs inevitable and are acting to create a new consensus about the future.

\section{Transition pathways in the visions}

Considering the four archetypal transition pathways (Geels and Schot, 2007), the central vision conforms best to the transformation pathway. While change is seen as inevitable following landscape pressures in the form of policies and targets to reduce greenhouse gas emissions, it is envisioned as gradual, linear and hardly disruptive, with the main elements of automobility unchanged: transport is centred around privately owned cars; users are seen as consumers or drivers with high transport demand; large companies will shift over to making LCVs. While the arrival of new entrants is certainly possible, change is slow enough to allow many ICEV-producing incumbent firms to adapt. The transition dynamic is of regime actors adopting new technologies, gradually and almost seamlessly replacing ICEVs with LCVs (probably EVs). In other words, the regime reorients its trajectory. This is not surprising, considering the visions come from regime actors with strong vested interests.

Using the visions, regime actors craft possible futures in a way that makes the continuity of the sociotechnical regime more plausible. This is strengthened when visions by different actors converge towards a consensus or 'central vision'. Regime actors seek certainty over future policy, as it is questionable whether LCVs can reach a big market without government regulation and investment in infrastructure and $R \& D$.

The transformation pathway sees incumbent manufacturers understanding the need for change, and over time 'gradually increasing use of electrification in the powertrain' (Kay et al., 2013, p. 125) as they develop EVs from existing models, all 
without relinquishing power. This suggests extensive experimentation with alternative technologies and fuels largely carried out or controlled by regime actors, in contrast to outsiders; it could be seen as niche absorption, making the regime more fit for purpose in a changing landscape through acquiring new attributes and changing its trajectory (Haxeltine et al., 2008). A similar dynamic is described in van Bree et al. (2010, p. 537): 'Once carmakers become convinced that they can no longer address further tightening of regulations via adaptations of existing technology $\ldots$ and that non-compliance will lead to substantial (financial) consequences, they scale up [fuel cell] and BEV experiments'.

In contrast, the 'revolutionary' trajectory (Kay et al., 2013) has elements of a technological substitution, where ICT-connected EVs taking off in cities leads to significant change in institutions and norms, disrupting the ICEV-based regime. The regime is found not fit for purpose when the landscape changes, and a more suitable niche innovation breaks through, changing not only the technology, but resulting in new travel norms and institutional changes.

In the Foresight visions (Curry et al., 2006), the 'Urban Colonies' scenario combines low-impact transport with strong public attitudes reducing acceptance of intelligent infrastructure, leading to a world where technological investment is focused on reducing environmental impact. Compact cities with a local focus reduce the need for travel, and transport is restricted to cleaner forms. This could be seen as a reconfiguration with extensive changes to infrastructure, institutions and travel norms, in contrast to the central vision.

The Foresight 'Tribal Trading' scenario (Curry et al., 2006) envisions a world after a severe energy shock, with the global economy damaged and infrastructure falling into disrepair. Transport has high environmental impact and is greatly reduced, with mobility no longer seen as a right. This trajectory has elements of de-alignment and re-alignment, where regimes collapse from strong pressure, and new ones emerge in a very different world. This contrasts sharply with the lack of disruption or discontinuity in the central vision.

In summary, disruptive change is unrealistically lacking in the central vision. The smooth transition does not take into account the radical nature of EVs which might rely on 'new functionalities' to succeed (Augenstein, 2015) as opposed to a direct one-for-one replacement of ICEVs with EVs. It is important to appreciate that the regime of automobility is not entirely homogeneous or free from tensions; one disruption clearly lacking in the visions is change in fuel provision, as road transport is the biggest global source of oil demand. A shift to EVs would affect supply chain actors in the automobility system, requiring a significant reconfiguration of part of the regime. The lack of disruption is also evident in the paucity of scenarios in which emission targets are missed. Even economic disruption (recession) is seen as temporarily reducing car sales and delaying LCV development and deployment but does not challenge the regime. This analysis suggests that the central vision is closest to the transformation pathway not because of inevitability or likelihood, but because it best suits incumbent actors' agendas. This use of visions could be defined as institutional work, as described below. 


\section{Visions as institutional work}

Creating visions can be seen as a strategy that regime actors use to maintain or restore institutional structures, by expressing expectations about the (long-term) future in order to influence the present (and near future). This section highlights some strategies deployed within these visions to neutralise the potentially disruptive nature of radical or niche innovations.

The visions show a varied, and sometimes contradictory, mix of imagined roles and responsibilities for government and policy. On the one hand, there are calls for non-meddling support for manufacturing, and on the other, recommendations that government work together with industry to develop the future of the automotive strategy in the UK. There are various calls for government to ensure funding for research and development $(R \& D)$ and not just basic research, and to guarantee long-term support for purchase in order to sustain demand, creating certainty for the industry. This suggests a recognition that creating a successful, sustained EV market is non-trivial and requires intervention and (financial) support. Uptake is seen as one of the biggest challenges and most documents identify ways to incentivise users through financial instruments, such as grants or subsidies for purchase, and some also suggest ways to raise awareness and improve EVs' image.

Both the call for government to tackle barriers to uptake and support the markets, and the focus on users and demand, arguably work to shift responsibilities for change away from manufacturers towards the state and civil society. These calls have a neoliberal character, minimising risk to the private sector and allowing industry actors their freedom without bearing full responsibility for emissions reduction targets, while potentially public and private sector grow closer. From an institutional perspective, this can be seen as enabling work, 'the creation of rules that facilitate, supplement and support institutions' (Lawrence and Suddaby, 2006, p. 230).

From a regulation perspective, documents from a range of actors call for gradually, but significantly, tightening emission targets. This would allow both improvement of ICEVs and increased uptake of LCVs, "[giving] the industry the required long-term security for investments in low-carbon car technology and infrastructure' (Dings, 2009, p. 7). There are calls for regulations to 'capture well-to-wheel (or even life cycle) emissions' (Kay et al., 2013, p. xi). However, this could increase uncertainties around $\mathrm{EV}$ s since their well-to-wheel and lifecycle emissions depend on the electricity grid and the wider vehicle manufacture process, respectively. Institutionally, this could be seen as a delay tactic, favouring incumbents in the short term, while allowing them time to adapt.

Many of the documents recommend 'technology neutrality', the assumption that with the right supporting policies, markets will choose the best options among fuel and engine technologies through competition and deliver required greenhouse gas emissions reductions with no major changes to mobility trajectories. Several documents call on government to ensure a level playing field rather than pick winners, stressing manufacturers' support for a technology 
neutral approach. Some government documents reaffirm allowing industry to develop the low-carbon technologies most appropriate for users. Government and industry seem to be reassuring each other through the narrative of technological neutrality, possibly a sign of a regime alliance between incumbents and policymakers (Geels, 2014). This could be interpreted simply as prudent government action in the face of technological uncertainty: hesitation by the state has been observed elsewhere in relation to EVs and is particularly likely when the free market paradigm prevails (Nykvist and Nilsson, 2015). For the industry, this could be another delay tactic that preserves the regime's stability as ICEV improvements can meet emission targets in the short term.

This analysis highlights the profoundly political nature of visioning, seeking to order the institutional constellation and identify and assign responsibilities to different groups of actors. Delay tactics prevent more profound changes, allowing more efficient ICEVs (or hybrids) to continue their dominance in coming years. Industry seeks close alliance with the government with public investment and assurances, while arguing for regulatory approaches that favour incumbents to minimise risk.

Finally, some factors are under-emphasised in the central vision. Behaviour changes beyond choice of vehicle for purchase are portrayed as marginal, and the heterogeneity of mobility patterns and complexity of awareness and acceptance of LCVs are simplified. Deeper changes to the automobility system are almost entirely absent. These could include infrastructural shifts, such as compact cities that reduce the need for personal motorised travel or shifting norms away from seeing high travel demand as normal and high mobility as a right. Even the observed trend of peak car is ignored. The central vision is limited in scope, hindering genuine transformation, as the unsavoury parts of the transition are downplayed, problematised or ignored.

\section{Conclusions and policy recommendations}

This chapter has analysed visioning documents of the future of the UK's system for personal transport, integrating lessons from transition pathways and institutional dynamics. The focus is on the role of $E V s$, in the context of growing landscape pressure of climate change-related policy to reduce greenhouse gas emissions from transport.

Some regime actors might consider LCVs to be inevitable, and others might be supporting EVs in order to hedge their bets, and to serve their agendas by influencing the future configuration of the system (Bakker, 2014). Either way, regime actors are working to define future trajectories and make the emerging niche as regime-symbiotic as possible, using visioning documents among other things. They work for slower change, by pressing for a continued high demand, private car-based personal transport system, which allows ICEVs to persist for years to come, and crucially - acts for LCVs to adapt to current automobility, rather than allowing the mobility system to adapt to and be shaped by these technologies. From a transitions perspective, when landscape pressures make the 
dynamically stable reproduction pathway untenable, some incumbents work towards a transformation pathway, which minimises disruption and allows many regime actors to maintain power.

One of the most striking features of the central vision is the focus on incremental change with an almost complete lack of discontinuities or serious disruptions to the regime or the transport system more generally. This matches other recent research that found that 'alternative visions of mobility that really might challenge the incumbent regime are rather rare' (Weyer et al., 2015, p. 20). This is unrealistic, as EVs cannot simply replace conventional cars without allowing new approaches to vehicle manufacture or design by new entrants (Kay et al., 2013), perhaps even redefining the role of the car in society (Augenstein, 2015). The fuel shift away from oil would itself be hugely disruptive to the system and is not engaged with in these trajectories. This vision is limited, and limiting, in scope, potentially preventing a deeper transition towards sustainability by locking out alternative futures and limiting EVs to the role of a techno-fix, rather than explore vast possibilities of electrical mobility. For example, EVs' role as electricity storage is a common topic in electricity futures, but its effect on travel practices should be considered in transport futures.

The main recommendation for policymakers is to engage with visions that include a larger variety of futures. These must include scenarios of disruption and shocks to the system, and possibilities of failing to meet emission reduction and other targets. This could be achieved by commissioning visioning documents from a larger variety of actors, including outsiders and niche players, who can challenge, rather than support, futures such as the central vision described here. This would offer more scope and choice for policymakers to meet policy goals and targets and leave us better prepared for foreseeable and unforeseeable changes to transport in the future.

\section{Notes}

1 This includes both battery-electric vehicles (BEVs) and plug-in hybrids.

2 In this chapter, trajectories describe possible unfolding transport futures, while pathways are theoretical, archetypal trajectories, like those detailed in the transitions literature.

3 For a detailed explanation of the methodology, see Bergman et al. (2017).

\section{References}

Anderson, B. (2010) Preemption, precaution, preparedness: Anticipatory action and future geographies. Progress in Human Geography 34(6): 777-798.

Augenstein, K. (2015) Analysing the potential for sustainable e-mobility - The case of Germany. Environmental Innovation and Societal Transitions 14: 101-115.

Bakker, S. (2014) Actor rationales in sustainability transitions - Interests and expectations regarding electric vehicle recharging. Environmental Innovation and Societal Transitions 13: 60-74.

Bakker, S. and Farla, J. (2015) Electrification of the car - Will the momentum last?: Introduction to the special issue'. Environmental Innovation and Societal Transitions 14: 1-4. 
Bergman, N. (2017) Stories of the future: Personal mobility innovation in the United Kingdom. Energy Research and Social Science 31: 184-193.

Bergman, N., Schwanen, T. and Sovacool, B.K. (2017) Imagined people, behaviour and future mobility: Insights from visions of electric vehicles and car clubs in the United Kingdom. Transport Policy 59: 165-173.

BERR and DfT (2008) Investigation into the Scope for the Transport Sector to Switch to Electric Vehicles and Plugin Hybrid Vehicles. Department for Business Enterprise and Regulatory Reform and Department for Transport, London, UK.

BNEF (2017) Big Oil Just Woke Up to Threat of Rising Electric Car Demand, Bloomberg New Energy Finance. Available at: https://about.bnef.com/blog/big-oil-just-woke-upto-the-threat-of-rising-electric-car-demand/.

van Bree, B., Verbong, G.P.J. and Kramer, G.J. (2010) A multi-level perspective on the introduction of hydrogen and battery-electric vehicles. Technological Forecasting and Social Change 77(4): 529-540.

Budde, B., Alkemade, F. and Weber, K.M. (2012) Expectations as a key to understanding actor strategies in the field of fuel cell and hydrogen vehicles. Technological Forecasting and Social Change 79(6): 1072-1083.

CCC (2010) The Fourth Carbon Budget: Reducing Emissions through the 2020s. Committee on Climate Change, London, UK.

CCC (2013) Fourth Carbon Budget Review - Technical Report: Sectoral Analysis of the Cost-effective Path to the 2050 Target. Committee on Climate Change, London, UK.

CCC (2014) Meeting Carbon Budgets - 2014 Progress Report to Parliament. Committee on Climate Change, London, UK.

Cohen, M.J. (2012) The future of automobile society: A socio-technical transitions perspective. Technology Analysis and Strategic Management 24(4):377-390.

Curry, A., Hodgson, T., Kelnar, R. and Wilson, A. (2006) Intelligent Infrastructure Futures: The Scenarios - Towards 2055. Department of Trade and Industry, London. Available at: www.foresightfordevelopment.org/library/55/1337-intelligent-infrastructure-futuresscenarios-toward-2055-perspective-and-process.

DECC (2011) The Carbon Plan: Delivering our Low Carbon Future. Department of Energy and Climate Change, London, UK.

Dijk, M., Orsato, R.J. and Kemp, R. (2015) Towards a regime-based typology of market evolution. Technological Forecasting and Social Change 92(C): 276-289.

Dings, J. (2009) How to Avoid an Electric Shock. Electric Cars: From Hype to Reality. Transport and Environment, Brussels.

Doughty, K. and Murray, L. (2016) Discourses of mobility: Institutions, everyday lives and embodiment. Mobilities 11(2): 303-322. DOI: 10.1080/17450101.2014.941257.

Driscoll, P.A. (2014) Breaking carbon lock-in: Path dependencies in large-scale transportation infrastructure projects. Planning Practice and Research 29(3): 317-330.

EST (2002) Pathways to Future Vehicles. Energy Saving Trust, London, UK.

EST (2007) Passenger Car Market Transformation Model. Energy Saving Trust, London, UK.

Fuenfschilling, L. and Truffer, B. (2014) The structuration of socio-technical regimes Conceptual foundations from institutional theory. Research Policy 43(4): 772-791.

Fuenfschilling, L. and Truffer, B. (2016) The interplay of institutions, actors and technologies in socio-technical systems - An analysis of transformations in the Australian urban water sector. Technological Forecasting and Social Change 103: 298-312.

Fujimura, J. (2003) Future Imaginaries: Genome Scientists as Socio-cultural Entrepreneurs. In: Goodman, A.H., Heath, D., Lindee, M.S. (Eds) Genetic Nature/ 
Culture: Anthropology and Science beyond the Two Culture Divide. University of California Press, Oakland, CA, USA, 176-199.

Geels, F.W. (2005) Processes and patterns in transitions and system innovations: Refining the co-evolutionary multi-level perspective. Technological Forecasting and Social Change 72(6): 681-696.

Geels, F.W. (2011) The multi-level perspective on sustainability transitions: Responses to seven criticisms. Environmental Innovation and Societal Transitions 1(1): 24-40.

Geels, F.W. (2012) A socio-technical analysis of low-carbon transitions: Introducing the multi-level perspective into transport studies. Journal of Transport Geography 24: 471-482.

Geels, F.W. (2014) Regime resistance against low-carbon transitions: Introducing politics and power into the multi-level perspective. Theory, Culture and Society 31(5): 21-40. DOI: $10.1177 / 0263276414531627$.

Geels, F.W. and Schot, J. (2007) Typology of sociotechnical transition pathways. Research Policy, 36(3): 399-417.

Geels, F.W. and Verhees, B. (2011) Cultural legitimacy and framing struggles in innovation journeys: A cultural-performative perspective and a case study of Dutch nuclear energy (1945-1986). Technological Forecasting and Social Change 78(6): 910-930.

Goodwin, P. and Van Dender, K. (2013) 'Peak car' - themes and issues. Transport Reviews 33(3): 243-254.

Haxeltine, A., Whitmarsh, L., Bergman, N., Rotmans, J. Schilperoord, M. and Kohler, J. (2008) A conceptual framework for transition modelling. International Journal of Innovation and Sustainable Development 3(1-2): 93-114.

Hazeldine, T., Kollamthodi, S., Brannigan, C., Morris, M. and Deller, L. (2009) Market Outlook to 2022 for Battery Electric Vehicles and Plug-in Hybrid Electric Vehicles, AEA Group, commissioned by the Committee on Climate Change, Oxfordshire, England.

HMG (2017) Building our Industrial Strategy: Green Paper. HM Government, London, UK. Available at: www.gov.uk/government/uploads/system/uploads/attachment_data/ file/611705/building-our-industrial-strategy-green-paper.pdf.

Kay, D., Hill, N. and Newman, D. (2013) Powering ahead: The future of low-carbon cars and fuels. Ricardo-AEA-RAC Foundation. Available at: www.racfoundation.org/wpcontent/uploads/2017/11/powering_ahead-kay_et_al-apr2013.pdf.

King, J. (2007) The King Review of Low-carbon Cars: Part I: The Potential for $\mathrm{CO}_{2}$ Reduction. HM Treasury, London, UK.

King, J. (2008) The King Review of Low-carbon Cars: Part II: Recommendations for Action. HM Treasury, London, UK.

Lane, B. (2011) Market Delivery of Ultra-Low Carbon Vehicles in the UK: An Evidence Review. RAC Foundation. Ecolane, London, UK.

Lawrence, T.B. and Suddaby, R. (2006) Institutions and Institutional Work. In: Clegg, S.R., Hardy, C., Lawrence, T.B. and Nord, W.R. (Eds) The SAGE Handbook of Organization Studies, SAGE, London, UK, Chapter 7.

Lente, H. van (1993) Promising technology: The dynamics of expectations in technological developments. PhD Thesis. Universiteit Twente The Netherland. ISBN: 90-5166-354-4.

Levidow, L. and Papaioannou, T. (2013) State imaginaries of the public good: Shaping UK innovation priorities for bioenergy. Environmental Science and Policy 30: 36-49.

McCormack, D.P. and Schwanen, T. (2011) Guest editorial: The space-times of decision making. Environment and Planning A 43(12): 2801-2818. 
National Grid (2015) Future Energy Scenarios: UK Gas and Electricity Transmission. National Grid, Warwick, UK.

Nykvist, B. and Nilsson, M. (2015) The EV paradox - A multilevel study of why Stockholm is not a leader in electric vehicles. Environmental Innovation and Societal Transitions 14: 26-44.

Paterson, M. (2007) Automobile Politics: Ecology and Cultural Political Economy. Cambridge University Press, Cambridge, UK.

Penna, C.C.R. and Geels, F.W. (2015) Climate change and the slow reorientation of the American car industry (1979-2012): An application and extension of the Dialectic Issue LifeCycle (DILC) model. Research Policy 44(5): 1029-1048.

Ruef, A. and Markard, J. (2010) What happens after a hype? How changing expectations affected innovation activities in the case of stationary fuel cells. Technology Analysis and Strategic Management 22(3): 317-338.

Schot, J. and Geels, F.W. (2008) Strategic niche management and sustainable innovation journeys: Theory, findings, research agenda, and policy. Technology Analysis and Strategic Management 20(5): 537-554.

Schwanen, T. (2015) Automobility. In: J.D. Wright (Ed.) International Encyclopedia of the Social and Behavioral Sciences. Elsevier, Oxford, UK, 303-308.

Smink, M.M., Hekkert, M.P. and Negro, S.O. (2015) Keeping sustainable innovation on a leash? Exploring incumbents' institutional strategies. Business Strategy and the Environment 24(2): 86-101.

SMMT (2017) Motor Industry Facts 2017. SMMT, London, UK. Available at: www. smmt.co.uk/reports/smmt-facts-2017/.

SMMT (2018) EV \& AFV Registrations: December 2017 and Year-to-Date, Society of Motor Manufacturers and Traders. SMMT, London, UK. Available at: www.smmt. co.uk/vehicle-data/evs-and-afvs-registrations/.

Straw, W. and Rowney, M. (2013) Leading the Charge: Can Britain Develop a Global Advantage in Ultra-low Emission Vehicles? Institute for Public Policy Research, London, UK.

Unruh, G. (2000) Understanding carbon lock-in. Energy Policy 28: 817-830.

Urry, J. (2004) The 'system' of automobility. Theory, Culture and Society 21(4-5): 25-39.

Walker, G., Cass, N., Burningham, K. and Barnett, J. (2010) Renewable energy and sociotechnical change: Imagined subjectivities of 'the public' and their implications. Environment and Planning A 42(4): 931-947.

Wells, P. and Nieuwenhuis, P. (2012) Transition failure: Understanding continuity in the automotive industry. Technological Forecasting and Social Change 79(9): 1681-1692.

Weyer, J., Hoffmann, S. and Longen, J. (2015) Achieving Sustainable Mobility. 44/2015. Dortmund. Available at: https://eldorado.tu-dortmund.de/bitstream/2003/34344/1/ Weyer_et_al_2015_Discontinuation_Automobility_AP-44.pdf. 